\title{
Synthetic studies in the mevinoid field. The total synthesis of ML236A
}

\author{
Samuel J. Danishefsky and Bruno Simoneau \\ Department of Chemistry, Yale University, New Haven, Connecticut 06511 U.S.A.
}

\begin{abstract}
The sequence of a lactonic Claisen rearrangement and a Lewis acid catalyzed cyclocondensation of an aldehyde with an appropriate diene affords a new route to the title series.
\end{abstract}

\section{BACKGROUND AND PURPOSE OF THE INVESTIGATION}

The discovery of the mevinoids, the recognition of their ability to sharply lower the levels of serum cholesterol and the identification of their mode of action via their inhibition of the enzyme HMG CoA reductase, have been important in cardiovascular medicine (ref. 1, 2). Since the formation of mevalonate from 3-hydroxy-3methylglutarate is apparently the limiting step in the mammalian biosynthesis of cholesterol (ref. 3), the inhibition of this enzyme is a particularly inviting target for medical intervention.

The studies described herein were formulated not only to reach these compounds, but were seen to have broad applications toward other important targets. After favorable demonstrations in model systems, it was then appropriate to demonstrate the scope of our findings via a total synthesis of the mevinoids (ref. 4).

The second inducement was the opportunity to learn more about the structural specificity for HMG CoA inhibition. Indeed, a great deal of effort has already gone into the study of the impact of molecular modifications of compounds derived from the natural products on biochemical performance (ref. 5). Many compounds which are much simpler than the mevinoids from the standpoint of structural complexity have been evaluated. Our intention was to provide access to targets bearing a close relationship to the naturally occurring inhibitors. The targets we had in mind could best be made by total synthesis. The assessment of the impact of these subtle structural changes would provide calibration for the validity of conformational modeling of the natural products and its relevance to HMG CoA inhibition. We have achieved our first goal, i.e., the total synthesis of ML-236A by new chemistry which is described below.

\section{SYNTHETIC PLANNING}

The problem was subdivided into its two obvious components - the "hexalin" and "pyranone" issues. The strategies we devised for these two sectors are implicit in Fig. 1. For entry to the hexalin subunit we contemplated a Claisen-like rearrangement of an enolate equivalent, derived from a 6-vinylvalerolactone (see $1 \rightarrow 2$ ). To reach the pyranone moiety, we proposed a cycloaddition reaction of an aldehyde (3) with a suitable diene (4). The formal cycloadduct $5 \mathrm{might}$ be amenable to transformation to the required substructure, 6 . 
The prospectus, shown in Fig. 1, deliberately leaves open many crucial particulars. For instance, in structure 1 we have not specified the nature of the substitution at $C_{5}$ of the lactone enolate. We defer explanation of the stereochemical assertion implicit in the transformation of $1 \rightarrow 2$. Similarly, we have not dealt with issues of stereochemistry in the pyranone subunit. Also unaddressed here is a protocol for advancement from 5 to 6.

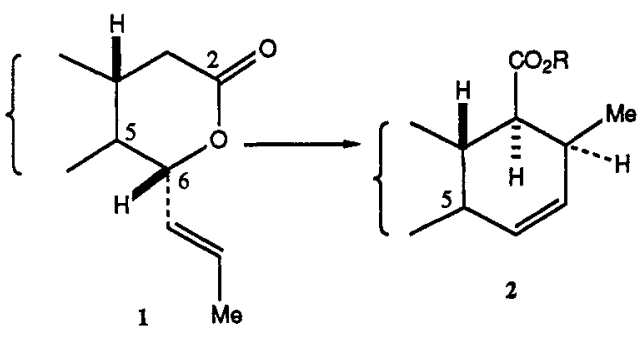<smiles>[X]C(=C)CCC</smiles><smiles>[B]C1C=C2C=C[C@@H](O)[C@H](CC[C@H]3CC(=O)C[C@@H](O)C3)[C@H]2[C@H](O)C1</smiles>

$\mathrm{R}=(\mathrm{S})$-2-methylbutyryl; $\mathrm{R}^{\prime}=\mathrm{H}=\mathrm{ML} 236 \mathrm{~B}=$ compactin $\mathrm{R}=\mathrm{R}^{\prime}=\mathrm{H}=\mathrm{ML} 236 \mathrm{~A}$

$\mathrm{R}=(\mathrm{S})-2$-methylbutyryl; $\mathrm{R}^{\prime}=\mathrm{Me}=$ mevinolin

Fig. 1

Two overall possibilities for harmonizing the construction of the subunits were considered. In the "chirality matching" approach, a moiety derived from 2 would be joined to an entity derived from 5 or $\mathbf{6}$, thus fashioning the "ethano spacer", connecting the two sectors. In an alternative "chirality communication" approach, the $\mathrm{R}$ group in $\mathbf{3}$ would already include the terpene-like residue derived from 2 . This is a more ambitious proposal in that it implies that the resident chirality of the terpenoid aldehyde will determine (in the desired sense) the facial selectivity of the cycloaddition. These two possibilities are implied in Fig. 2.

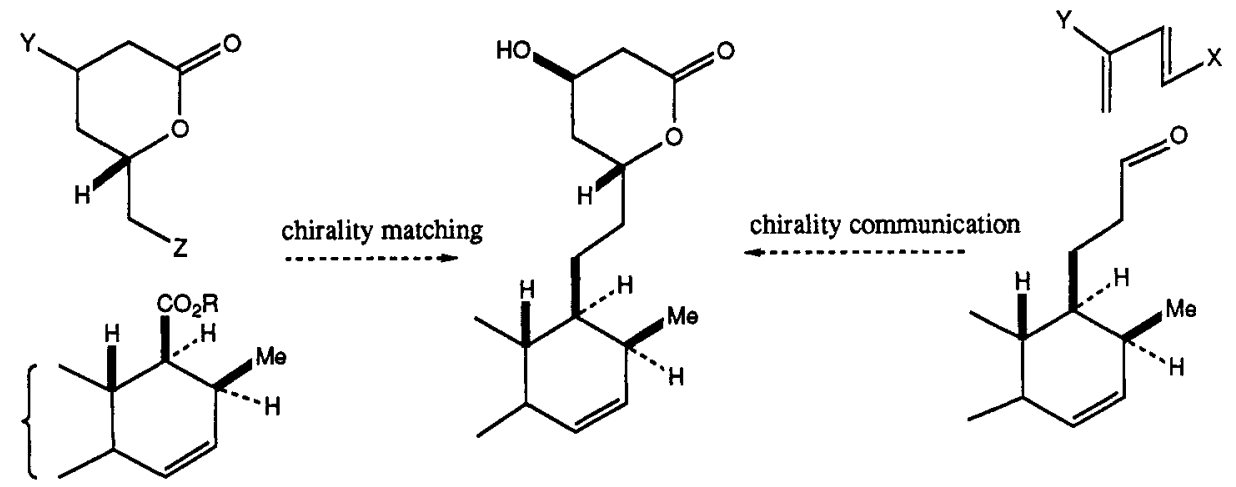

Fig. 2 


\section{EARLY FINDINGS}

James Kerwin found that with a wide variety of aldehydes and dienes, in the presence of various Lewis acid catalysts, transformations such as $3+4 \rightarrow 5$ do indeed occur (ref. 6). At this writing, some six years after our initial disclosures on the process, there seems little need to dwell upon the scope of the reaction which Kerwin developed (ref. 7), its stereochemical patterns (ref. 8), achievements of absolute asymmetric induction (ref. 9), or the applications to a variety of total syntheses (ref. 10). On the matter of the reaction courses (ref. 11), suffice it to say that given the plurality of pathways, we prefer the term "cyclocondensation" (ref. 12), which focuses on gross structural changes rather than "cycloaddition", which is suggestive of a mechanistic commitment.

Even as ideas are offered in the broadest of terms, it is well to recall that one of our early reports in the cyclocondensation field anticipated an application to introduce the required stereochemical pattern (ref. 13). Boron trifluoride etherate catalyzed reaction of benzyloxyacetaldehyde with diene 6 afforded 8, presumably via 7 . Addition of isopropanol to 8 gave the axial glycoside 9. Reduction of the ketone with L-Selectride gave quite cleanly the axial alcohol 10. It was assumed that 10 could be converted to the desired lactone prototype 11 at a suitable stage of the synthesis.

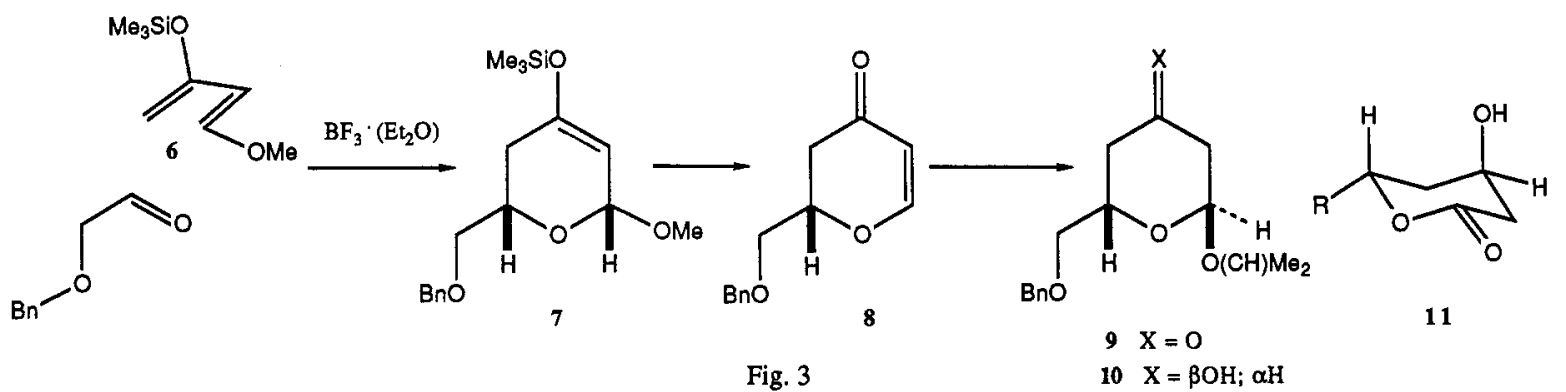

Even earlier than our observations concerning the cyclocondensation reaction, was our demonstration that the lactone (silyl) enolate Claisen rearrangement was indeed viable and that its stereochemical outcome was amenable to a high degree of definition (ref. 14, 15). The transformation of $\mathbf{1 2}$ to $\mathbf{1 3}$ demonstrates the consequences of the rigid boatlike transition state imposed by the constraints of the cyclic array. Not the least compelling is the requirement that the final endocyclic double bond be $Z$. The lactonic enolate rearrangement process thus produces a different outcome, with higher specificity than is obtained from the Ireland ester (silyl) enolate rearrangement from which it drew analogy (ref. 16, 17).

The transformation of $\mathbf{1 4}$ to $\mathbf{1 5}$, used in a stereospecific total synthesis of widdrol, demonstrates another advantage of conducting the reaction in the cyclic series. The high fidelity of the chirality transmission in the rearrangement can be used to define the relative stereochemistry of the emerging carboxyl group with resident stereogenicity. Thus, the cyclic process has the equivalent of perfect facial selectivity (see Fig. 4).

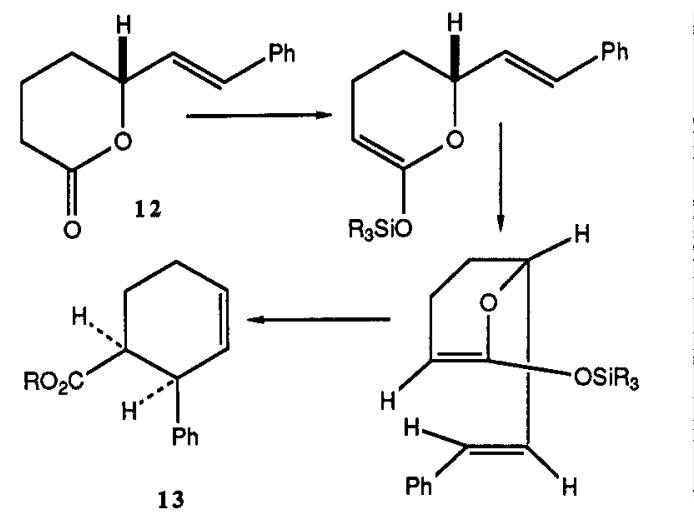

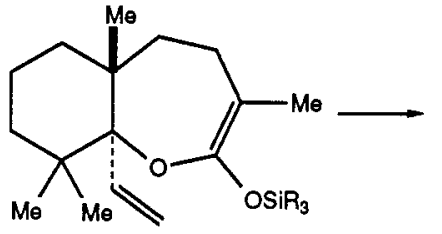

14

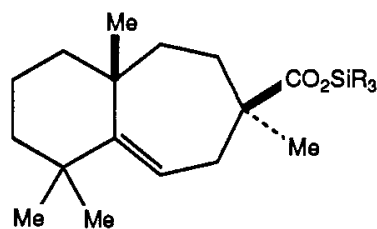

15 
Given these findings, our initial plan for synthesizing the hexalin portion of compactin envisioned recourse to a vinylic lactone such as 16. Rearrangement of this compound via a silylketeneacetal would be expected to produce 17. Unfortunately, we encountered very serious difficulties in our attempts to obtain the required 16. Thus, reaction of $E$-propenyllithium with enal 18 afforded the epimeric lactone 19 in a highly selective fashion. A variety of attempts to convert 19 to the desired 16 in synthetically useful amounts were unsuccessful. A serious problem in this regard was the rather limited stability of both 16 and 19 (as well as their open hydroxy ester forms) and the difficulties in separating mixtures of these closely related epimers (ref. 18).

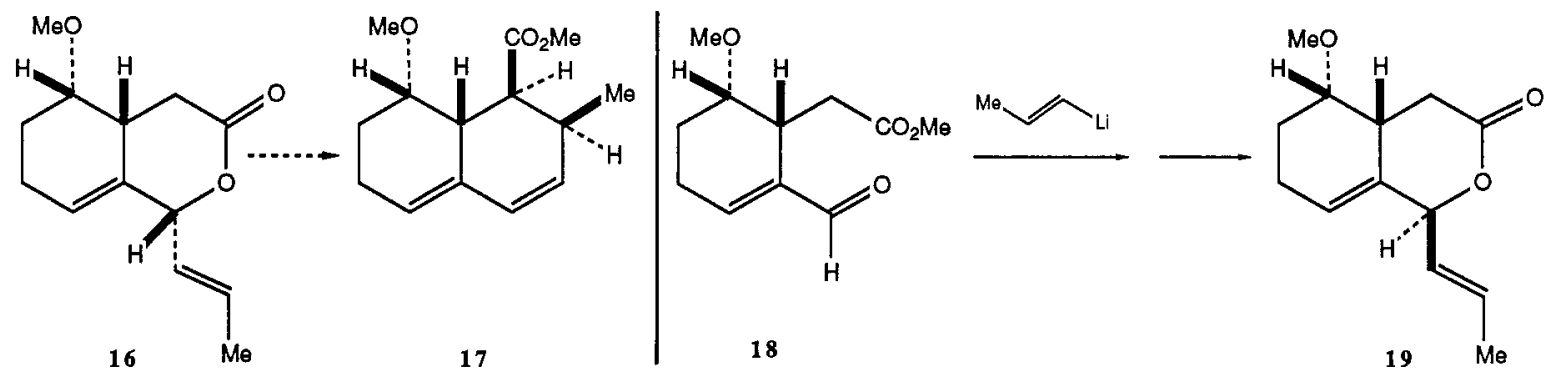

Fig. 5

\section{DISCUSSION OF RESULTS}

A recent disclosure by Mukaiyama (ref. 19) provided a lead which encouraged us to take up the hexalin problem anew, though in a context which differed from the scenario indicated in Fig. 5. As we have reported (ref. 20), reaction of cyclohexenone with the OTBS silylketeneacetal derived from methyl propionate afforded 20 . Reaction of 20 with crotonaldehyde (21) followed by lactonization gave rise to 22 . The enoxysilane silylketeneacetal 23, underwent smooth Claisen rearrangement to produce an $80 \%$ yield of 24 , with the silyl enol ether in tact. For the moment we have not exploited the enoxysilane functionality. Hydrolysis and esterification of 24 afforded 25 (see Fig. 6).

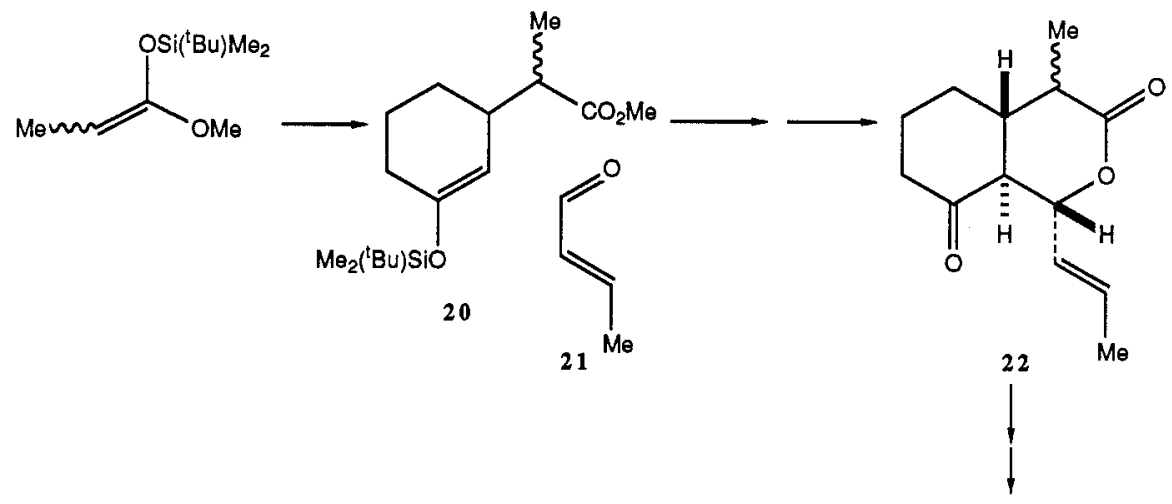

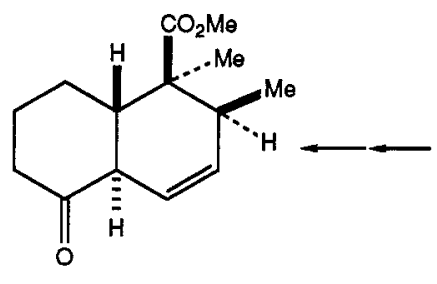

25

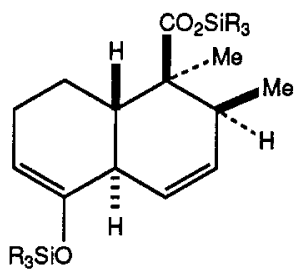

24

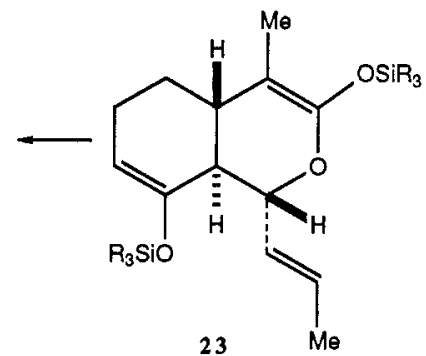

23 
A similar sequence, employing a 4- functionalized derivative of cyclohexenone could accommodate the oxygen function required for compactin-mevinolin. Of course, the inclusion of such an additional group raised an obvious new stereochemical issue, i.e., the face selectivity of the initial Mukaiyama reaction (ref. 19).

At approximately this time, our laboratory developed a route leading from quinic acid to the $S$ enantiomer of 4-TBSO cyclohexenone $26 \mathrm{~S}$ (ref. 21, 22). In principle we were prepared to accept the formation of either trans $27 \mathrm{t}$ or cis $27 \mathrm{c}$ adducts in the "grouptransfer" reaction. If, as might be expected from superficial analysis, the former had pertained, it would have been necessary to devise a route to $(26 \mathbf{R})$ enantiomer and to invert the stereochemistry at the 8 carbon (compactin numbering, ref. 23) at some stage of the synthesis.

In studying the course of nucleophilic additions to 26 rac, an interesting observation was made. Whereas methylation via lithium dimethyl cuprate occurs trans to the silyloxy group, several Lewis acid catalyzed processes produce 3,4-cis product with high selectivity (ref. 24). We are currently in the process of sorting out the structural and mechanistic features responsible for this very high syn selectivity. For the present we note that this result is extremely convenient for a synthesis of the mevinoids in that it allows us to use the readily available $26 \mathrm{~S}$ enantiomer without the need for inversion of $\mathrm{C}_{8}$.<smiles>O=C(O)[C@]1(O)C[C@@H](O)[C@H](O)[C@H](O)C1</smiles><smiles>[X]C1CCC(=O)CC1</smiles>

$26 \mathrm{~S} X=\alpha \mathrm{OTBS} ; \beta \mathrm{H}$

26R $\mathrm{X}=\beta \mathrm{OTBS} ; \alpha \mathrm{H}$

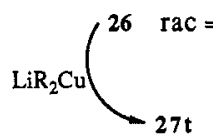

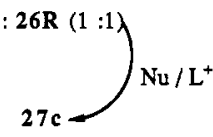<smiles>CCCC[C@]1(O)CCC(=O)C[C@H]1N</smiles>

27t<smiles>CCCC1CCC(=O)C[C@H]1N</smiles>

$27 \mathrm{c}$ trans addition $26 \mathrm{R}$

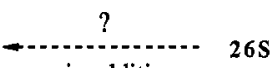

cis addition

Fig. 7

We preferred, in the first instance, to explore the possibility of "chiralitycommunication" in the cycloaddition reaction leading to the dihydropyrone (see Fig. 2). Therefore, there was no need for us to work with enantiomerically pure aldehyde type 3. The issues of facial selectivity and relative stereochemistry could be explored equally well in the racemic series. Accordingly, we could start with racemic 26 for our initial studies. In this spirit we defined as our first goal in this series ML236A, in which the awkwardness of a stereogenic center on the acyl side chain is absent.

Reaction of $26 \mathrm{rac}$ with 28 in the presence of mercuric iodide (ether $-78^{\circ} \mathrm{C}$ ) afforded a $90 \%$ yield of 29. The $\mathrm{C}_{3}-\mathrm{C}_{4}$ trans epimer (cyclohexanone numbering), not shown here, could be detected in ca. $4 \%$ yield. Boron trifluoride etherate catalyzed reaction of 29 with crotonaldehyde (21) at $-78^{\circ} \mathrm{C}$ occurred with a second silyl transfer in a highly stereoselective fashion. The resultant product, when treated with trifluoroacetic acid, afforded the lactone 30, though only at present in $40 \%$ yield. Given the value of this intermediate, the conciseness of its synthesis (three steps from 26), and its usefulness (vide infra), this yield could be characterized as disappointing rather than fatal to the program. 
The stage was set for lactonic Claisen rearrangement. Enol silylation of both the ketonic and ester functions afforded $\mathbf{3 1}$ which underwent smooth bond reorganization in toluene at $105^{\circ} \mathrm{C}$. Hydrolysis of the carboxy and enol silyloxy functions could be achieved while leaving the secondary silyloxy function in tact. Esterification (diazomethane) afforded the ketoester $\mathbf{3 2}$ in an overall yield of $78 \%$. It was a straightforward matter to convert the $\beta, \gamma$-unsaturated ketone to the bicyclic diene using literature precedents (ref. 25, 26). Reduction of 32 with L-Selectride gave axial alcohol 33. The latter, upon activation with methanesulfonyl chloride gave mesylate 34 .<smiles>CC(C)(C)O[C@H]1C=CC(=O)CC1</smiles>

$26(\mathrm{rac})$<smiles>[X]C1CCC(OS(C)(=O)=O)[C@H]2[C@H](C(C)=O)[C@@](C)(CC)C=C[C@@H]12</smiles>

$32 \mathrm{X}=0$

$33 \mathrm{X}=\beta \mathrm{OH} ; \alpha \mathrm{H}$

$34 \mathrm{X}=\beta \mathrm{OSO} 2 \mathrm{Me} ; \alpha \mathrm{H}$

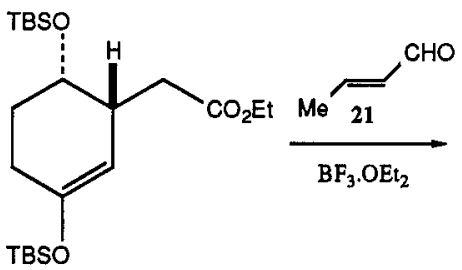

29<smiles>COC1=C[C@H]2[C@@H](OC(C)C)CC=C(OC)[C@H]2[C@H](/C=C/S)O1</smiles>

31<smiles>C/C=C/[C@H](OCC)[C@@H]1C(=O)CCC(OCC)[C@@H]1CC(=O)OCC</smiles>

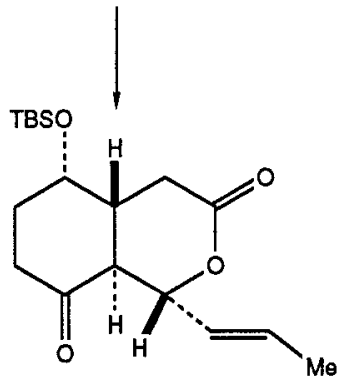

30

Fig. 8

Trans diaxial elimination of the homoallylic mesylate 34 (DBU pyridine; $105^{\circ} \mathrm{C}$ ) gave rise to $35(80 \%)$. The ester was reduced (diisobutylaluminum hydride) to alcohol 36 . Swern oxidation gave aldehyde 37. Two-carbon extension was achieved by an Emmons reaction (ref. 27). Conjugate reduction of the resultant 38, was best accomplished with magnesium in methanol. Reduction of the ester (diisobutylaluminum hydride) afforded alcohol 40 (70\% overall from 37).

Based on precedents from the work of Uskokovic and Wovkulich (ref. 28), it appeared that an acetoxy group at $\mathrm{C}_{8}$ would be more effective than a silyloxyl function for promoting face selectivity in the cyclocondensation reaction. It was thus necessary to go through several steps to achieve the transformation of OTBS to OAc.

De-silylation of 40 with HF in acetonitrile and selective silylation of diol 41 at the primary hydroxyl group gave 42. Acetylation of the secondary alcohol afforded 43 . De-silylation followed by Swern oxidation gave the required aldehyde 44 (ca. $60 \%$ from 40) We could now test the feasibility of diastereoselection in the cyclocondensation reaction.

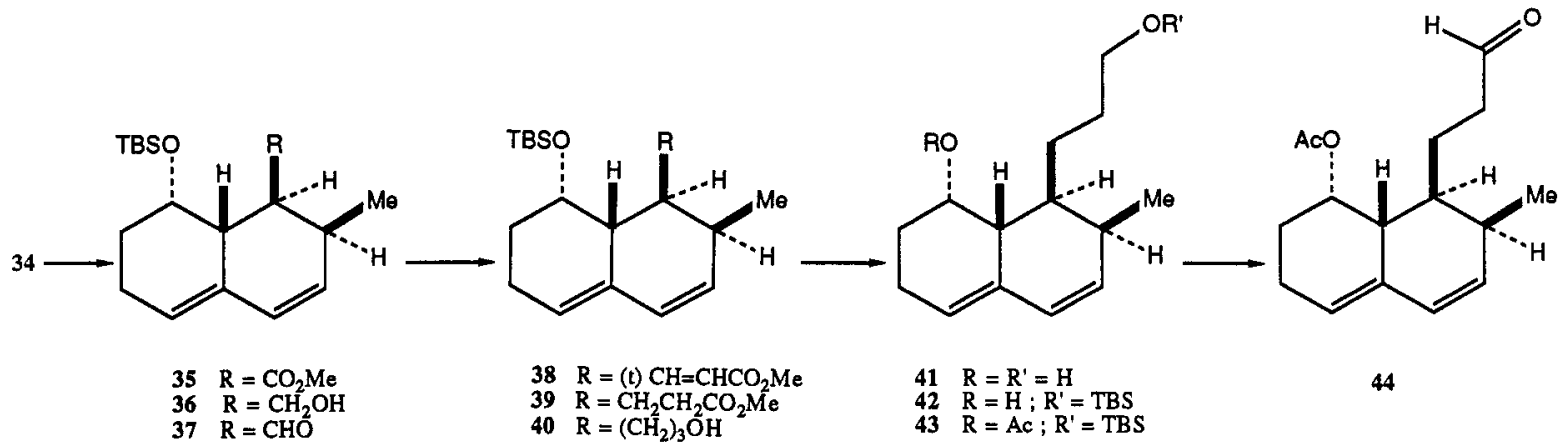


As alluded to above, we were much guided, in defining the character of our oxygen substituent at $\mathrm{C}_{8}$ and the experimental conditions, by experiments which were conducted by Wovkulich and Uskokovic (ref. 28) on a different but related substrate. In our case we have resorted to diene 45, using titanium tetrachloride in methylene chloride. The resultant product consisted of a mixture of dihydropyrones (46 and 47) (ref. 29a), as well as aldol-like structures (48 and 49) (ref. 29b). The total material was submitted to cyclization with trifluoroacetic acid. Overall there was obtained a $70 \%$ yield of 46 and 47 in a $4: 1$ ratio.

At the time, we could not rigorously assign stereochemistry at $C_{12}$ to these compounds. That the major one in fact has the desired $\mathrm{R}$ configuration was demonstrated by carrying it through to racemic ML-236A. The previously described protocol (ref. 13) was followed. Ethanolysis of $\mathbf{4 6}$ afforded the axial glycoside 50. This set the stage for LSelectride reduction giving the $\mathrm{C}_{14}$ axial alcohol 51. Hydrolysis of the ethyl glycoside followed by oxidation with silver carbonate-celite gave the rac ML-236A acetate 52 (41\% overall from the dihydropyrone 46). De-acetylation with lithium hydroxide occurred uneventfully to complete the total synthesis of racemic ML-236A (53). In a similar sequence $\mathbf{4 7}$ was converted to $\mathbf{5 4}$, wherein the stereochemical relationship of the two chiral sectors is opposite to that of 53. Indeed, the NMR spectroscopic properties of $\mathbf{5 4}$ differ in nuance from those of an authentic sample, while those of fully synthetic $\mathbf{5 3}$ are identical.

With the completion of this total synthesis, several goals become accessible. First, we are already using the $26 \mathrm{~S}$ enantiomer to reach the targets in their appropriate chiral forms. Also, in the enantiomerically homogeneous series, our program to prepare novel analogs by total synthesis is well under way. Finally, we note that applications of this new chemistry to important targets ranging from prostanoids to the fusarium toxin are already bearing fruit.

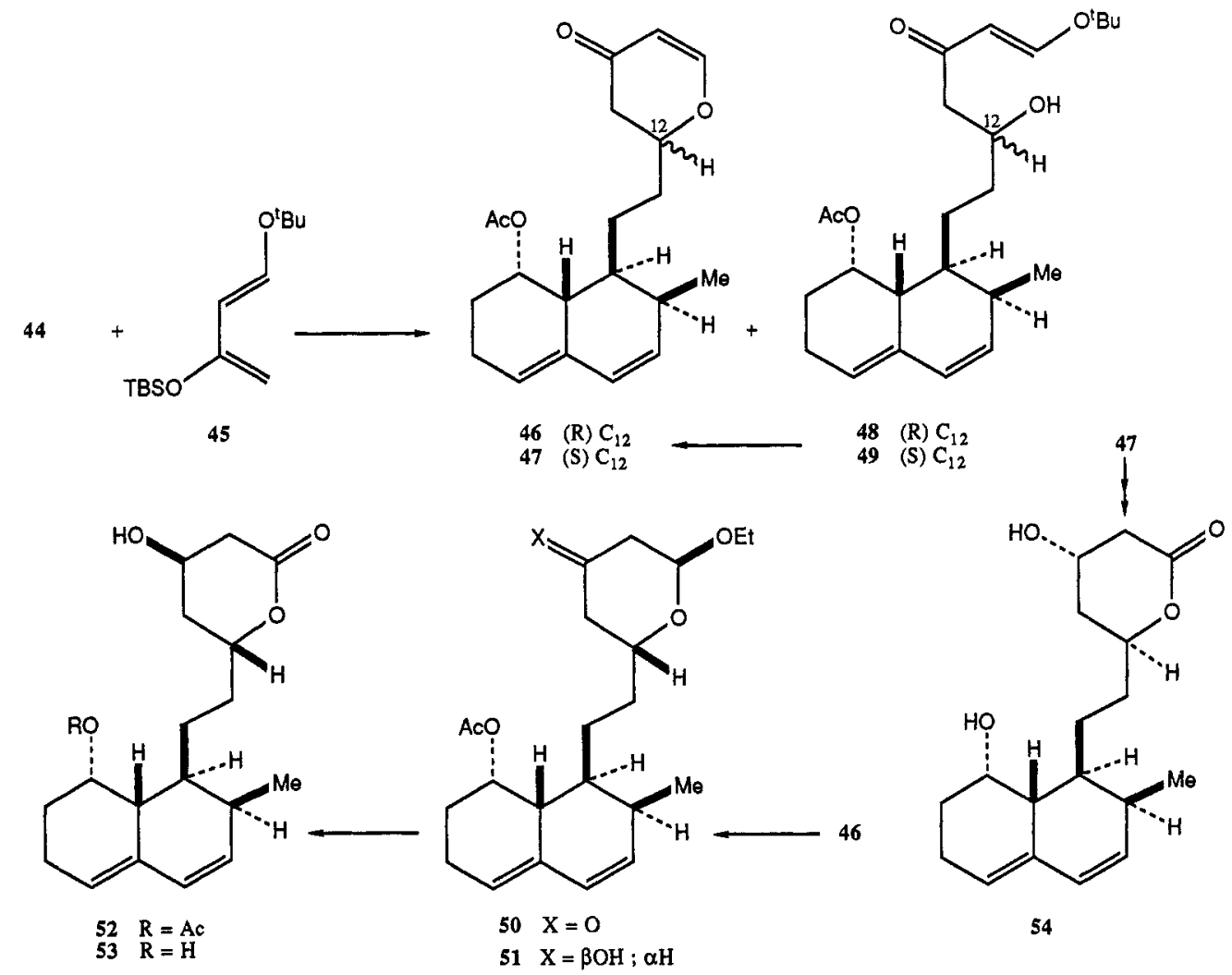

Fig. 10 


\section{Acknowledgements}

This research was supported by PHS Grant HL-25848. An NSERC Postdoctoral Fellowship to B.S. is gratefully acknowledged. NMR spectra were obtained through the auspices of the Northeast Regional NSF/NMR Facility at Yale University, which was supported by NSF Chemistry Division Grant CHE 7916210.

\section{REFERENCES}

1. (a) A. Endo, M. Kuroda, Y. Tsujita, L. Antibiot. 29, 1346-1348 (1976). (b) A. W. R Roberts, J. Chen, G. Kuron, V. Hunt, J. Huff, C. Hoffman, J. Rothrock, M. Lopez, H. Joshua, E. Harris, A. Patchett, R. Monaghan, S. Currie, E. Stapley, G. AlbersSchonberg, O. Hensens, J. Hirshfield, K. Hoogsteen, J. Liesch, J. Springer, Proc. Natl. Acad. Sci. USA 77, 3957-3961 (1980). (c) N. Serizawa, K. Nakagawa, K. Hamano, Y. Tsujita, A. Terahara, H. Kuwano, J. Antibiot. 36, 604-607 (1983).

2. A. Endo, L. Med. Chem. 28, $401-405$ (1985) and references therein.

3. R. Fears, In 3-Hydroxy-3-Methylglutaryl Coenzyme A Reductase, J. R. Sabine, Ed.; CRC: Boca Raton, FL, 1983; Chapter 14.

4. For an excellent compilation of references on mevinic acids, see: T. Rosen, C.H. Heathcock, Tetrahedron 42, 4909-4951 (1986).

5. C.H. Heathcock, C.R. Hadley, T. Rosen, P.D. Theisen, S.J. Hecker, J. Med. Chem. 30, 1858-1873 (1987) and references therein.

6. S. Danishefsky, J.F. Kerwin, Jr., S. Kobayashi, L. Am. Chem. Soc. 104, 358-360 (1982).

7. S.J. Danishefsky, E. Larson, D. Askin, N. Kato, J. Am. Chem. Soc. 107, 1246-1255 (1985).

8. S.J. Danishefsky, W.H. Pearson, D.F. Harvey, C.J. Maring, J.P. Springer, I. Am. Chem. Soc. 107, 1256-1268 (1985).

9. M. Bednarski, S. Danishefsky, I. Am. Chem. Soc. 108, 7060-7067 (1986).

10. S.J. Danishefsky, Aldrichimica Acta 19, 59-68 (1986).

11. E.R. Larson, S. Danishefsky, Tetrahedron Lett. 23, 1975-1978 (1982).

12. Under the term cyclocondensation we include the common cases aldol-like intermediates generated and subsequently cyclized to dihydropyrones.

13. S. Danishefsky, S. Kobayashi, J.F. Kerwin, Jr., J. Org. Chem. 47, 1981-1983 (1982).

14. S. Danisehfsky, R.L. Funk, J.F. Kerwin, Jr., J. Am. Chem. Soc. 102, 6889-6891 (1980).

15. S. Danishefsky, K. Tsuzuki, Ibid. 102, 6891-6893 (1980).

16. R.E. Ireland, R.H. Mueller, Ibid. 24, 5897-5898 (1972).

17. R.E. Ireland, R.H. Mueller, A.K. Willard, Ibid. 98, 2868-2877 (1976).

18. T. Sommers, Yale University, unpublished results (1982).

19. S. Kobayashi, T. Mukaiyama, Chem. Lett. 1805-1808 (1986).

20. S.J. Danishefsky, J.E. Audia, Tetrahedron Lett. 29, 1371-1374 (1988).

21. B.M. Trost, A.G. Romero, J. Org. Chem. 51, 2332-2342 (1986). Two-step transformation of (-)-quinic acid: acetonide formation and lactonization followed by $\mathrm{LAH}$ reduction.

22. J.E. Audia, L. Boisvert, Yale University, unpublished results.

23. A.G. Brown, T.C. Smale, T.J. King, R. Hasenkamp, R.H. Thomson, J. Chem. Soc. Perkin Trans. I 1165-1170 (1976).

24. In addition to the reaction shown here, the addition of allylsilane and the $\mathrm{BF}_{3} \cdot \mathrm{OEt}_{2}$ catalyzed Diels-Alder Cycloaddition with 1,3-butadiene occur cis to the OTBS group with high selectivity. On the other hand, the cuprate addition occurs trans to the OTBS group with high selectivity. M. Yamaguchi and M.P. Cabal, Yale University, unpublished results.

25. C.-T. Hsu, N.-Y. Wang, L.H. Latimer, C.-J. Sih, J. Am. Chem. Soc. 105, 593-601 (1983).

26. N.N. Girotra, N.L. Wendler, Tetrahedron Lett. 23, $5501-5504$ (1982).

27. (a) Mg reduction: I.K. Youn, G.H. Yon, C.S. Pak, Tetrahedron Lett. 27, 2409-2410

(1986). (b) W.S. Wadsworth, W.D. Emmons, I. Am. Chem. Soc. 83, 1733-1738 (1961).

28. The work on the cyclocondensation of a closely related aldehyde was first conducted at the Hoffmann-La Roche Co., Nutley, NJ. We thank Drs. M.R. Uskokovic and P.M. Wovkulich for apprising us of their results and of their dramatic selectivity differences as a function of the $C_{8}$ oxygen protective group.

29. (a) ratio of dihydropyrones 46 and 47, 3:1. (b) ratio of aldols 48 and 49, 5:1 